\title{
A língua, as línguas, o pensamento: apontamentos de leitura de Categorias de pensamento e categorias de língua
}

Valdir do Nascimento Flores"

\section{Resumo}

Este trabalho visa examinar o artigo de Émile Benveniste, Categorias de pensamento e categorias de língua, de 1958, publicado novamente, em 1966, no livro Problemas da Linguística Geral 1. O objetivo geral é apresentar como Benveniste pensa a relação entre pensamento e linguagem. Para fazer isso, em primeiro lugar, é apresentado o contexto de aparição do artigo; em seguida, faz-se uma leitura do artigo, tentando estabelecer os principais pontos de reflexão do autor. Finalmente, as conclusões são formuladas. Este texto conclui destacando as seguintes relações: o pensamento e o símbolo, a língua e a realidade, a língua e as línguas.

Palavras-chave: Pensamento. Linguagem. Língua. Línguas. Símbolo.

\section{Introdução}

$\mathrm{O}$ artigo Categorias de pensamento e categorias de língua, publicado por Benveniste originalmente em 1958 e republicado em Problemas de linguística geral I, em 1966, lançou luzes sobre um tema que, historicamente, tem indagado os linguistas: o das relações entre o pensamento e a língua.

Sobre esse artigo, há muitas e controversas opiniões. De um lado, os filósofos: não são poucos os autores que se contrapuseram às ideias de Benveniste expostas em Categorias ${ }^{1}$. Foi assim com Derrida (1971), Aubenque (1965) e Vuillemin (1967). Em todos, vê-se uma forte crítica dirigida a Benveniste, em especial, devido o recurso a Aristóteles.

\footnotetext{
Professor Titular em Língua Portuguesa do Instituto de Letras da Ufrgs. Pesquisador CNPq. E-mail: valdirnf@ yahoo.com.br
}

Data de submissão: set. 2018 - Data de aceite: out. 2018 http://dx.doi.org/10.5335/rdes.v14i3.8539 
De outro lado, os teóricos da tradução. É assim com Georges Mounin (1975, p. 54-56 e p.203), George Steiner (2002, p. 135) e Oustinoff (2001, p. 20). Nestes últimos, reconhece-se a importância do texto no contexto de abordagem da diversidade das línguas em sua relação com o pensamento e com a realidade.

Tendo em vista essa duplicidade de compreensão do texto - ao que tudo indica, os teóricos da tradução são mais receptivos ao artigo do que os filósofos - este trabalho pretende, a seguir, apresentar uma leitura de Categorias com a intenção de retomar os principais argumentos avançados por Benveniste, em especial, com relação ao papel da língua na relação com o pensamento, no contexto da diversidade das línguas.

Para tanto, em um primeiro momento, são feitas considerações gerais acerca do texto e em relação ao contexto de sua aparição; em seguida, são apresentadas as grandes linhas de compreensão do artigo para finalmente tecer-se a conclusão.

\section{Categorias no contexto geral e de Problemas de linguística geral I}

$\mathrm{O}$ artigo Categorias de pensamento e categorias de línguas apareceu, originalmente, no número 4 da revista Études Philosophiques, dedicado aos estudos da linguagem, junto aos seguintes textos ${ }^{2}$ : Pensée et grammaire (Jean Fourquet); Observation et explication dans la scien- ce du langage (Gustave Guillaume); Le coup de dés de Stéphane Mallarmé et le message (Jean Hyppolite); Qu'est-ce que parler le même langage? (André Jacob); Monde et langage: réflexions sur la philosophie du langage de Wilhelm von Humboldt (Lothar Kelkel); Wittgenstein, le langage et la philosophie (Albert Shalom); La voix qui pense et sa pensée: Martin Heidegger (Richard Wisser and Lothar Kelkel).

Como é fácil notar, trata-se de um contexto eminentemente filosófico. Conforme Laplantine (2011),

Benveniste lembra aos filósofos que jamais se pode pretender atingir as realidades, as essências, os universais [...], mais que isso ele mostra que uma invenção do pensar é necessariamente uma invenção de gramática (LAPLANTINE, 2011, p. 91).

Quando é republicado, Categorias aparece em um contexto mais próximo de reflexões antropológicas. Trata-se do conjunto de textos do primeiro volume dos Problemas de linguística geral, abrigados na segunda parte do livro, que, sob o rótulo A comunicação, traçam um viés de abordagem da problemática da natureza de linguagem (linguageira) do homem. Gerard Dessons, exímio leitor de Benveniste, considera que

a noção de comunicação é um elemento fundamental do pensamento de Benveniste sobre a linguagem e, mais que isso, da antropologia linguística que constrói sua teoria da enunciação (DESSONS, 2006, p. 43).

Ainda sobre a comunicação, diz Dessons: 
[...] a comunicação, tal como a teoriza Benveniste, é menos relevante para as teorias da informação, para as quais comunicar significa essencialmente transmitir mensagens, do que para uma antropologia do valor, que torna indissociáveis o ato de comunicar e a elaboração de valores constitutivos da sociedade humana como fatos de cultura (2006, p. 43).

Nesses artigos, Benveniste apresenta uma face do que chama - no Prefácio de Problemas I - uma "contribuição ao grande problema da linguagem" (BENVENISTE, 1988). Ele parte da definição de signo linguístico (cf. Natureza do signo linguístico) para, então, caracterizar a linguagem humana em contraste com a comunicação animal (cf. Comunicação animal e linguagem humana); em seguida, discute as relações entre pensamento e linguagem (cf. Categorias de pensamento e categorias de língua) para, finalmente, tratar da linguagem em sua relação com o inconsciente (cf. A função da linguagem na descoberta freudiana).

Que fio condutor há entre esses textos que lhes permite figurar sob o mesmo rótulo? Tendo-se em mente que a organização do primeiro volume dos Problemas fora feita pelo próprio Benveniste - o que não é válido para o segundo volume, organizado por M. DJ. Moïnfar -, essa pergunta recobre-se de maior relevância. Por que Benveniste reuniu-os em A comunicação? A resposta, segundo penso, decorre da própria organização dessa parte do livro: Benveniste, com ela, anuncia que a comunicação humana - que é bem distinta da animal - tem a propriedade de "comunicar" o humano porque, além de ser de base signica - 0 primeiro texto dessa parte é justamente Natureza do signo linguístico - , não pode ser descolada do que o rodeia: a cultura, o pensamento etc. Isso é o que a diferencia.

A leitura transversal dos textos reunidos sob a égide de $A$ Comunicação permite ver um ponto que eles não evidenciam separadamente: o que é "comunicado" transcende a pura mensagem. O "comunicado" - o sentido, a cabeça de Medusa - encontra lugar no signo, sem dúvida, mas também em todas as outras faces do humano. Aceitar isso leva à excelente conclusão de Boulbina em seu pequeno dossier ${ }^{3}$ sobre $A$ comunicação em Benveniste:

as questões da linguística não engajam somente a linguística, mas também a filosofia, a antropologia, e muitas outras disciplinas ainda (BOULBINA, 2009, p. 116).

A comunicação humana, assim entendida, é apenas a face exterior de uma propriedade muito maior e mais complexa: a linguagem.

\section{As linhas argumentativas de Categorias}

$\mathrm{O}$ artigo de Benveniste, para fins de apresentação, pode ser dividido em cinco momentos: a formulação do problema; os encaminhamentos; a análise; a formulação de resposta ao problema; uma demonstração e, finalmente, a conclusão.

A formulação do problema: Benveniste parte de duas considerações acerca 
dos usos da língua: de um lado, consiste no fato de que "a realidade da língua permanece, via de regra, inconsciente" (BENVENISTE, 1988, p. 68); de outro, consiste no fato de que "por mais abstratas ou particulares que sejam as operações do pensamento, recebem expressão na língua" (BENVENISTE, 1988, p. 68).

Essas considerações, apresentadas por Benveniste quase como constatações tácitas, são fonte de muitas ambiguidades e a principal diz respeito à convicção de a língua apresentar os recursos "ao espírito para o que chamamos a expressão do pensamento" (BENVENISTE, 1988, p. 68). "Esse é o problema que encaramos sumariamente aqui" (BENVENISTE, 1988, p. 68).

Eis o problema do qual parte Benveniste: o fato de que "podemos dizer tudo, e podemos dizê-lo como queremos" (BENVENISTE, 1988, p. 68) implica afirmar que a língua expressa o pensamento?

Observe-se que há uma diferença importante aqui entre considerar que as operações de pensamento recebem expressão na língua e afirmar que a língua permite a expressão do pensamento.

Para dar conta dessas indagações iniciais, Benveniste tenta circunscrever o que chama de "pensamento":

[...] "o que queremos dizer" ou "o que temos no espírito' ou 'o nosso pensamento" (seja lá como for que o designemos) é um conteúdo de pensamento, bem difícil de definir em si mesmo (BENVENISTE, 1988, p. 69).

Nesse ponto, Benveniste formula uma tese forte:
Esse conteúdo recebe forma quando é enunciado, e somente assim. Recebe forma da língua e na língua, que é o molde de toda expressão possível; não pode dissociar-se dela e não pode transcendê-la (BENVENISTE, 1988, p. 69).

Ou ainda: a língua "dá a sua forma ao conteúdo de pensamento" (BENVENISTE, 1988, p. 69).

Deve-se estar atento aqui a dois pontos ${ }^{4}$ : a) o conteúdo de pensamento recebe forma "da" e "na" língua; b) a língua dá "sua" forma (em itálico na passagem original) à língua e não "a” forma ou mesmo apenas "forma" à língua. Quanto ao primeiro, é justo reconhecer que "língua" é entendida, simultaneamente, como meio e modo de realização; quanto ao segundo, impõe-se perceber que Benveniste entende que o pensamento tem uma forma que é "a sua", a qual é, por sua vez, como a forma da língua. Se se entende "forma", no sentido de organização - que é exatamente como Benveniste a entende ao dizer que a língua é "organizada como combinação de 'signos" (BENVENISTE, 1988, p. 69) conclui-se que o pensamento é organizado "como" a língua é organizada.

É isso que o leva a concluir que a forma da língua é condição de transmissão e de realização do pensamento: "não captamos o pensamento a não ser já adequado aos quadros da língua. Fora isso, não há senão obscura volição" (BENVENISTE, 1988, p. 69).

Mais uma vez, cabe chamar a atenção aqui, pois os termos podem ser enganadores: esse raciocínio de Benveniste não implica dizer que a língua dá uma forma 
ao conteúdo de pensamento ou mesmo que a língua tem formas prontas que servem para transmitir o pensamento. Benveniste nega isso ao recorrer à ideia do continente conteúdo:

[...] falar de continente e conteúdo é simplificar. A imagem não deve enganar. Estritamente falando, o pensamento não é uma matéria à qual a língua emprestaria forma, pois em nenhum momento esse 'continente' pode ser imaginado vazio de seu 'conteúdo', nem o 'conteúdo' como independente do seu 'continente' (BENVENISTE, 1988, p. 69-70).

Além do mais, o raciocínio apresentado até aqui não passa de pura constatação de uma relação de fato, pois

[...] apresentar esses dois termos, pensamento e língua, como solidários e mutuamente necessários não nos indica a forma pela qual são solidários, nem a razão por que os julgaríamos indispensáveis um ao outro (BENVENISTE, 1988, p. 69).

Em outras palavras, não basta dizer que um não existe sem o outro se não se explica a relação específica que há entre eles, afinal é evidente que os termos não são sinônimos.

Eis, então, o problema tal como Benveniste o reformula: apesar de se reconhecer a estreita relação entre pensamento e língua, é possível reconhecer algo que seja exclusivo de um e de outro?

Os encaminhamento: Benveniste trata o problema pela via das "categorias". Quer dizer, em um primeiro momento poder-se-ia dizer que "o pensamento pode pretender apresentar categorias universais, mas que as categorias linguísticas são sempre categorias de uma língua em particular" (BENVENISTE, 1988, p. 70), o que confirmaria certa independência e superioridade do pensamento em relação à língua.

Assim, ele passa a estudar as categorias de Aristóteles, tomadas como espécie "dados", ou ainda, como

[...] inventário das propriedades que um pensador grego julgava predicáveis a um objeto, e consequentemente como a lista dos conceitos a priori que, segundo ele, organizam a experiência (BENVENISTE, 1988, p. 70-71).

Em outras palavras, Benveniste toma a obra de Aristóteles ${ }^{5}$ como corpus de exame rigoroso das categorias de um pensamento e de uma língua definidos, no caso, o grego.

A análise: observe-se a tradução literal proposta por Benveniste do texto original de Aristóteles:

Cada uma das expressões que não entram numa combinação significa: a substância; ou quanto; ou qual; ou relativamente a que; ou onde; ou quando; ou estar em posição; ou estar em estado; ou fazer; ou sofrer. "Substancia", por exemplo, em geral, "homem"; "cavalo"; - "quanto", por exemplo, "de dois côvados; de três côvados"; - "qual”, por exemplo, "branco; instruído"; - "relativamente a que", por exemplo, "duplo; meio; maior"; - "onde", por exemplo, "no Ginásio; no mercado"; - "quando", por exemplo, "ontem; no ano passado"; - "estar em posição", por exemplo, "está deitado; está sentado"; "estar em estado", por exemplo, "está calçado; está armado"; - "fazer", por exemplo, "corta; queima"; - "sofrer", por exemplo, "é cortado; é queimado" (BENVENISTE, 1988, p. 71).

Tradicionalmente, assim se apresentam as categorias: (1) substância, (2) quantidade, (3) qualidade, (4) relação, (5) lugar, (6) tempo, (7) posição, (8) posse, (9) ação e (10) paixão. 
Como se pode ver, a tradução de Benveniste evidencia um ponto poucas vezes destacado, qual seja, o da relação entre as categorias e a língua grega. Observe-se a seis primeiras categorias

A "substância", (1), indica o substantivo; o "quanto", (2), a quantidade (o "ser-quantésimo", quantidades discretas, o número propriamente dito, ou quantidades contínuas); a categoria "qual", (3), indica 0 adjetivo ("qual-idade" sem acepção de espécies); a "relativamente a que", (4), indica elementos em si mesmos relativos (o conceito de "duplo" ou de "meio") ou as especificidades dos adjetivos de possuírem uma forma comparativa; a "onde", (5), indica o espaço, o advérbio; a "quando", (6), o tempo, também advérbio.

Essas seis primeiras categorias "referem-se todas a formas nominais. É na particularidade da morfologia grega que encontram sua unidade" (BENVENISTE, 1988, p. 73). São um conjunto.

As quatro categorias finais também formam conjunto: "são todas categorias verbais" (p. 73): a categoria "fazer", (9), indica a voz ativa do verbo; a "sofrer", (10), a voz passiva do verbo. Quanto às duas outras categorias, a (7) e a (8), é justo dizer que com relação a elas Benveniste demostra toda a sua erudição. Observe-se.

Pode-se questionar sobre o interesse de uma categoria como a (7), posição. Que valor teria? A resposta está nos exemplos "está deitado" e "está sentado" que na morfologia grega correspondem à voz média. Benveniste chega a afirmar que no sistema verbal do grego antigo a distinção mais importante era realmente entre 0 ativo e o médio. Isso quer dizer que

[...] sob o aspecto da língua, essa é uma noção essencial. Contrariamente ao que nos pareceria, o médio é mais importante que o passivo que dele deriva (BENVENISTE, 1988, p. 74).

Quanto à categoria (8), posse, ela não deve ser tomada no sentido habitual de "ter", posse material. Os exemplos aqui também são esclarecedores: "está calçado" e "está armado". Benveniste classifica-os como formas verbais do perfeito médio que, em grego, não tem apenas valor temporal, mas indica também, conforme o caso, um modo da temporalidade ou uma maneira de ser do sujeito, o que se sobressai nos exemplos ao traduzi-los incluindo a noção de "ter": "tem os calçados no pé" e "tem as armas sobre si”. Segundo Benveniste,

concebe-se, tendo em vista o número de noções que só se exprimem em grego sob a forma do perfeito, que Aristóteles o tenha tornado num modo específico do ser, o estado (ou habitus) do sujeito (BENVENISTE, 1988, p. 75).

O que essa análise de Benveniste coloca em destaque é absolutamente original: a língua grega é colocada em relação com as categorias de pensamento. É isso que o leva a concluir que é possível "transcrever em termos de língua a lista das dez categorias" (BENVENISTE, 1988, p. 75). Para Benveniste, Aristóteles, ao propor a "tábua das categorias" pensava arrolar os predicados da proposição, no entanto, não percebe que faz isso com as distinções que o grego manifesta: 
Pensava definir os atributos dos objetos; não apresenta senão seres linguísticos: a língua que, graças as suas próprias categorias, permite reconhecê-las e especificá-las (BENVENISTE, 1988, p. 76).

A tese é forte e precisa ser melhor detalhada.

A formulação de resposta ao problema: após essa análise, Benveniste crê ter reunido as condições para responder o problema que apresenta no início do artigo:

Temos assim uma resposta para a questão apresentada no inicio e que nos levou a esta analise. Perguntávamo-nos de que natureza eram as relações entre categorias de pensamento e categorias de língua. $\mathrm{Na}$ medida em que as categorias de Aristóteles se reconhecem válidas para o pensamento, revelam-se como a transposição das categorias de língua. É o que se pode dizer que delimita e organiza o que se pode pensar. A língua fornece a configuração fundamental das propriedades reconhecidas nas coisas pelo espirito. Essa tábua dos predicados informa-nos, pois; antes de tudo, sobre a estrutura das classes de uma língua particular (BENVENISTE, 1988, p.76, grifos meus).

De fato, a explicação de Benveniste é incontestável e seus argumentos são irrefutáveis. Sua tese é absolutamente comprovável: a análise categorial de Aristóteles decorre da estrutura específica da língua em que fora formulada, no caso, o grego.

No entanto, há ainda uma segunda tese, decorrente desta, que está bem clara na passagem acima: se as categorias aristotélicas são as categorias do grego segue-se que as categorias de pensamento são categorias de língua, o que encontra eco na afirmação acima de que "É o que se pode dizer que delimita e organiza o que se pode pensar".

Benveniste (1988), para comprovar essa segunda tese, procede de uma maneira completamente nova: ele examina a noção grega de "ser", presente no verbo grego "ser", para afirmar que a língua grega permitiu, com o seu verbo "ser", fazer do "ser" uma noção filosófica ${ }^{6}$, e faz isso contrapondo o valor do verbo "ser" em grego - e em boa parte das línguas indo-europeias - à distribuição que tem na língua ewe, falada no Togo. Observe-se a demonstração.

Conforme Benveniste (1988), a língua ewe distribui a noção de "ser" em muitos verbos. O linguista lista cinco:

a) Nyé - marca a identidade entre o sujeito e o predicado ("ser quem", "ser o que");

b) Le - exprime a existência (Mawu le, "Deus existe"); tem também emprego predicativo de situação, de localização ("estar num lugar, num estado, num tempo, numa qualidade"): e-le nyuie ("ele está bem"), e-le a fi ("ele está aqui"), (e-le ho me ("ele está em casa");

c) Wo - significa "fazer, cumprir, produzir um efeito", em combinação com um termo indicador de matéria, permite predicação (wo com ke "areia" = "estar/ser arenoso"7; com tsi "água" = "estar úmido"). O que se apresenta como um "ser" de natureza em francês, Il "fait" du vent, "está ventando", é um "fazer" em ewe; 
d) $D u$ - indica predicação relativa a um termo de função, de dignidade: $d u$ fia = "ser rei";

e) $D i$ - empregado com certos predicados de qualidade física, de estado: $d i k u=$ "estar magro"; $d i$ $f_{o}=$ "ser devedor".

Essa demonstração serve para Benveniste afirmar que os cinco verbos em ewe correspondem aproximativamente ao nosso verbo "ser". O linguista faz isso ressalvando que essa demonstração é feita a partir do exterior do ewe e não do interior. Quer dizer, usa-se a "nossa" língua, a língua indo-europeia, para descrever as cinco possibilidades presentes em ewe, no entanto,

[...] no interior da morfologia ou da sintaxe ewe, nada aproxima esses cinco verbos entre eles. É com relação aos nossos próprios usos linguísticos que lhes descobrimos qualquer coisa em comum (1988, p. 79).

Segundo ele, essa análise "egocêntrica" esclarece melhor o próprio grego na medida em que coloca luzes sobre um fato que é próprio das línguas indo-europeias e não uma situação universal ${ }^{8}$.

A conclusão: Benveniste conclui seu artigo convicto de que pode refutar duas ilusões, de sentido opostos, acerca do tema que o mobilizou.

A primeira ilusão é a de que a língua seja "apenas um dos intermediários do pensamento". Não. Para Benveniste quando "tentamos atingir os quadros próprios do pensamento, só nos apoderamos das categorias da língua" (1988, p. 79), logo ela é o grande intermediário; a segunda ilusão, inversamente, é a de que a língua seria "o decalque de uma 'lógica' inerente ao espírito, [...], exterior e anterior à língua" (1988, p. 79). Ambas são tautológicas. Isso leva Benveniste a concluir, em relação ao problema colocado no começo - se a língua expressaria o pensamento -, que a língua é condição do pensamento. Nem expressão, nem decalque, mas condição.

\section{Conclusões acerca dos apontamentos de leitura}

A leitura feita acima permite expor alguns pontos conclusivos que dizem respeito aos encaminhamentos possíveis acerca da reflexão esboçada aqui. Para mim, a prospecção da teoria benvenistiana, a partir de Categorias, está sintetizada no título deste artigo: trata-se das relações entre a língua, as línguas e o pensamento.

Como evidência disso, observe a conclusão de Benveniste em Categorias:

Sem dúvida, não é fortuito o fato de que a epistemologia moderna não tente constituir uma tábua das categorias. É mais produtivo conceber o espirito como virtualidade que como quadro, como dinamismo que como estrutura. É inegável que, submetido às exigências dos métodos científicos, o pensamento adota em toda parte os mesmos meios em qualquer língua que escolha para descrever a experiencia. Nesse sentido, torna-se independente, não da língua, mas das estruturas linguísticas particulares. $\mathrm{O}$ pensamento chinês pode muito bem haver inventado categorias tão específicas como o $\operatorname{tao}^{9}$, o yin e o $y a n^{10}:$ nem por isso é menos capaz de assimilar os conceitos da dialética materialista ou da mecânica quântica sem que a estrutura da língua chinesa a isso se 
oponha. Nenhum tipo de língua pode por si mesmo e por si só favorecer ou impedir a atividade do espirito. $\mathrm{O}$ voo do pensamento liga-se muito mais estreitamente às capacidades dos homens, às condições gerais da cultura, à organização da sociedade que à natureza particular da língua. A possibilidade do pensamento liga-se à faculdade de linguagem, pois a língua é uma estrutura informada ${ }^{11}$ de significação e pensar é manejar os símbolos da língua.

A citação é longa, mas é necessária. Nela, Benveniste coloca alguns pontos essenciais:

- Os meios do pensamento - notadamente quando este é submetido aos métodos científicos - se repetem (são “os mesmos”), independentemente da estrutura linguística particular. Isso conduz Benveniste a afirmar que, ao menos em certo sentido, o pensamento independe das línguas embora não independa da língua. Ora, isso é quase contraditório com o raciocínio exposto antes a respeito das categorias de Aristóteles, uma vez que Benveniste considera que, vale repetir, "Aristóteles, raciocinando de maneira absoluta, reconhece simplesmente certas categorias fundamentais da língua na qual pensa" (BENVENISTE, 1988, p. 71), no caso, o grego. Isso me leva a indagar: o que são esses "mesmos meios" presentes em "qualquer língua" que permitem "descrever a experiência"? A resposta parece vir adiante: “a possibilidade do pensamento liga-se à faculdade de linguagem", faculdade esta definida, posteriormente, no artigo de 1963, Vista d'olhos sobre o desenvolvimento da linguística, como "a mais alta forma de uma faculdade que é inerente à condição humana, a faculdade de simbolizar". Nesse sentido, pode-se compreender que "os mesmos" meios que o pensamento tem para "descrever a experiência", independentemente do idioma (grego, ewe, etc.), são os meios do símbolo, pois "pensar é manejar os símbolos da língua".

- Apesar de as operações do pensamento receber sempre "expressão na língua”, esta não é um limitador dessa expressão. O mesmo chinês que inventou o Tao compreende a dialética materialista. Isso quer dizer que, sendo a língua "uma estrutura informada de significação" em que a função simbólica da linguagem opera, o homem, como animal simbólico que é, está sempre sob o império das línguas. Cabe lembrar aqui uma bela formulação de Jakobson, justamente em um texto sobre tradução: "as línguas diferem essencialmente naquilo que devem expressar. $\mathrm{E}$ não naquilo que podem expressar" (JAKOBSON, 1974, p. 69). Nos termos de Benveniste: pode-se expressar a dialética materialista em qualquer língua, mas é mister que se atente para como isso deve ser feito em cada língua. 


\section{Langue, langues, pensée: notes de lecture de Catégories de pensée et catégories de langue}

\section{Resumé}

Ce travail a pour but d'examiner l'article d'Émile Benveniste, Catégories de pensée et catégories de langue, 1958, publié en 1966 dans l'ouvrage intitulé Problèmes de la linguistique générale 1. L'objectif général est de présenter comme Benveniste pense la relation entre pensée et langage. Pour ce faire, dans un premier temps, le contexte d'apparition de l'article est présenté; alors l'article est lu, essayant d'établir les points principaux de réflexion de l'auteur. Enfin, les conclusions sont formulées. Ce texte conclut en soulignant les relations suivantes: la pensée et le symbole, la langue et la réalité, la langue et les langues.

Mots-clés: pensée; langage; langue; langues; symbole.

\section{Notas}

1 O artigo Categorias de pensamento e categorias de língua também será referido aqui pela palavra Categorias. A edição utilizada é a brasileira, presente em Problemas de linguística geral I (cf. Referências). Quando necessário, a edição francesa foi também consultada (cf. Referências).

2 Disponível em: <https://www.jstor.org/stable/ i20842780>.

3 BOULBINA, Seloua Luste. "Dossier". In: BENVENISTE, E. La comunication: extrait de Problémès de linguistique générale. Paris, Folioplus, Philosophie, 2009.

4 Esses pontos também são lembrados por Laplantine (2011, p. 71-72), embora com propósitos ligeiramente distintos dos meus aqui.

5 As categorias é o primeiro texto do Organon conjunto dos tratados de lógica de Aristóteles.
6 Benveniste considera o "ser" "a condição de todos os predicados" (BENVENISTE, 1988, p. 76). No grego, ele tem empregos que abarcam a função lógica (cópula), a função nominal (posposto ao artigo), pode servir de predicado a si mesmo, etc.

7 A tradução brasileira opta por "estar areento".

8 Neste ponto é que os filósofos, em especial Derrida (cf. supra), reagiram contrariamente: Benveniste chega a sugerir certa relativização da metafísica ocidental, na medida em que considera que a estrutura do grego predispõe a noção de "ser" a uma vocação filosófica. Como disse acima, não seguirei o viés filosófico, mas o leitor interessado se beneficiará bastante da discussão presente em Laplantine (2011, p. 69-92).

9 Termo de filosofia e religião chinesas.

10 Também grafados como Yin-Yang, são termos da filosofia oriental chinesa, ligada ao taoísmo.

11 Em francês, "enformée". A tradução brasileira propõe "enformada"; eu prefiro "informada". Para entender o valor de "informada" aplicada à teoria de Benveniste, ver Normand (2009) em Referências.

\section{Referências}

AUBENQUE, Pierre. Aristote et le langage, note annexe sur les catégories d'Aristote. A propos d'un article de M. Benveniste. Annales de la facultés des Lettres d'Aix, v. XLIII, Aix-em-Province, n. 43, p. 85-105, 1965.

BENVENISTE, Emile. Catégories de pensée et catégories de langue. In: Problèmes de linguistique générale, 1. Paris: Gallimard, 1966.

BENVENISTE, Émile. Categorias de pensamento e categorias de língua. In:

Problemas de linguística geral I. Campinas: Pontes, 1988 (tradução de Maria da Glória Novak e Maria Luiza Neri).

BOULBINA, Seloua Luste. "Trois questions posées au texte". In: BENVENISTE, E. La comunication: extrait de Problémès de linguistique générale. Paris, Folioplus, Philosophie, 2009. 
DERRIDA, Jacques. Le supplément de copule. La philosophie devant la linguistique. Langages, Paris, n. 24, p. 14-39, 1971.

DESSONS, Gérard. Émile Benveniste: l'inventions du discours. Paris: Éditions in Press, 2006.

FLORES, Valdir do Nascimento. Introdução à teoria enunciativa de Benveniste. São Paulo: Parábola, 2014.

JAKOBSON, R. Aspectos linguísticos da tradução. In: . Linguística e Comunicação. São Paulo: Cultrix, 1974. (Tradução de José Paulo Paes, Isidoro Blikstein).

LAPLANTINE, Chloé. Émile Benveniste, l'inconscient et le poème. Limoges : Lambert-Lucas, 2011.

MOUNIN, Georges. Os problemas teóricos da tradução. São Paulo: Cultrix, 1975. (Tradução: Heloysa de Lima Dantas).

NORMAND, Claudine. Convite à linguística. São Paulo: Contexto, 2009.

OUSTINOFF, Michael. Tradução: história, teorias e métodos. São Paulo: Parábola, 2011. (tradução de Marcos Marcionilo).

STEINER, George. Depois de Babel: aspectos da linguagem e tradução. Lisboa: Relógio D’água, 2002. (Tradução: Miguel Serras Pereira).

VUILLEMIN, Jule. De la logique à la théologie. Cinq études sur Aristote. Paris: Flammarion, 1967. 